\title{
Trocas intelectuais entre Alemanha e América Latina: entrevista com Stefan Rinke
}

\author{
Intellectual exchange between Germany and Latin America: \\ an interview with Stefan Rinke
}

Entrevista com

\author{
Stefan Rinke \\ Professor e pesquisador do Instituto \\ de Estudos Latino-americanos/Freie \\ Universität Berlin. \\ Rüdesheimer Straße 54-56 \\ 14197 - Berlin - Alemanha \\ rinke@zedat.fu-berlin.de
}

Concedida a

\section{André Felipe Cândido da Silva}

Pós-doutorando do Departamento de História/Faculdade de Filosofia Letras e Ciências Humanas/ Universidade de São Paulo. Avenida Professor Luciano Gualberto, 315, Cidade Universitária 05508-900 - São Paulo - SP andrefelipe@usp.br

\section{Miriam Junghans}

Doutoranda do Programa de Pósgraduação em História das Ciências e da Saúde (PPGHCS)/Casa de Oswaldo Cruz (COC)/Fiocruz. miriamjung@gmail.com

\section{Juliana Manzoni Cavalcanti}

Pós-doutoranda do PPGHCS/COC/ Fiocruz.

jujumanzoni@yahoo.com.br

\section{Pedro Felipe Neves de Muñoz}

Doutorando do PPGHCS/COC/ Fiocruz.

pedrodemunoz@hotmail.com

PPGHCS/COC/Fiocruz.

Av. Brasil, $4036 / 4^{\circ}$ andar

21040-361 - Rio de Janeiro - RJ

- Brasil
SILVA, André Felipe Cândido da; JUNGHANS, Miriam; CAVALCANTI, Juliana Manzoni; MUÑOZ, Pedro Felipe Neves de. Trocas intelectuais entre Alemanha e América Latina: entrevista com Stefan Rinke. História, Ciências, Saúde - Manguinhos, Rio de Janeiro, v.21, n.1, jan.-mar. 2014, p.333-347.

\section{Resumo}

Acadêmico que se dedica a pensar o desenvolvimento histórico da América Latina levando em consideração sua inserção no concerto internacional, o historiador alemão Stefan Rinke, da Universidade Livre de Berlim, é entrevistado por alunos e ex-alunos da Casa de Oswaldo Cruz/ Fiocruz. Dimensões diversas como as relações econômicas e diplomáticas, os fluxos migratórios e os conflitos étnicos constituem, nos trabalhos de Rinke, meios de análise das redes de interdependência que ataram a América Latina à Europa e aos EUA. Suas reflexões extrapolam o âmbito do continente latino-americano e permitem pensar a globalização como processo histórico, situando contextos nacionais e regionais num quadro geral. Na entrevista Rinke fala sobre sua trajetória acadêmica, história global/transnacional e projetos conjuntos entre a Alemanha e a América Latina.

Palavras-chave: história global/história transnacional; relações EuropaAmérica Latina; relações Brasil-Alemanha; Stefan Rinke (1965- ).

\section{Abstract}

Current and former students of the Casa de Oswaldo Cruz/Fiocruz interviewed German historian Stefan Rinke, of the Freie Universität Berlin, who specializes in examining the historical development of Latin America as it fits into the international context. Rinke's work uses dimensions such as economic and diplomatic relations, migratory flows, and ethnic conflict as tools in his analyses of the networks of interdependence that have tied Latin America to Europe and the USA. His lens goes beyond the Latin American continent to approach globalization as a historical process, with national and regional contexts placed within a general framework. In this interview, Rinke talks about his academic career, global and transnational history, and joint projects between Germany and Latin America.

Keywords: global history/transnational history; European-Latin American relations; Brazilian-German relations; Stefan Rinke (1965- ).

http://dx.doi.org/10.1590/S0104-59702014000100006 
$\mathrm{N}^{\circ}$ otícia divulgada no site do Instituto de Estudos Latino-americanos da Universidade Livre de Berlim informa que Stefan Rinke, professor titular de história da América Latina daquele centro, será o primeiro pesquisador a receber financiamento da Fundação Einstein Berlim. Por dois anos Rinke pesquisará o impacto da Primeira Guerra Mundial no continente latino-americano. Em sua opinião, o evento "mudou a perspectiva latino-americana da ordem global". ${ }^{1}$

O informe não só dá conta dos caminhos de pesquisa e reflexão que o historiador trilhará no futuro próximo, como demonstra, no contexto de sua trajetória pregressa, o dinamismo de um acadêmico que se dedica a pensar o desenvolvimento histórico da América Latina levando em consideração sua inserção no concerto internacional. Dimensões diversas, como as relações econômicas e diplomáticas, os fluxos migratórios e os conflitos étnicos constituem nos trabalhos de Rinke meios de análise das redes de interdependência que ataram a América Latina à Europa e aos EUA, bem como promoveram a integração regional.

Graduado em história pela Universidade de Bamberg, uma das mais antigas do estado da Baviera, tendo também frequentado a Bowling Green State University nos EUA, Rinke desenvolveu sua tese de doutorado na Universidade Católica de Eichstätt, sob orientação do historiador alemão Hans-Joachim König. Analisou, entre 1990 e 1995, as relações dos países latino-americanos com a Alemanha durante a República de Weimar do ponto de vista das relações políticas, diplomáticas, comerciais, militares e culturais, dos movimentos migratórios e da política de fomento da "germanidade" (Deutschtum), também contemplando a propaganda cultural por meio da imprensa e as iniciativas envolvendo alemães e latinoamericanos no campo da aviação. Em 1996 foi publicado, em dois volumes, "Der letzte freie Kontinent”: Deutsche Lateinamerikapolitik im Zeichen transnationaler Beziehungen, 1918-19332 (“'O último continente livre': a política alemã para a América Latina sob o signo das relações transnacionais”). A obra, resultante desse ambicioso programa intelectual perseguido por meio de intensa investigação empírica, tornou-se referência obrigatória para os estudiosos interessados na história da América Latina e da Alemanha.

Concluído o doutorado, Rinke dedicou-se, entre 1995 e 1998, à pesquisa de pósdoutoramento como bolsista da Deutsche Forschungsgemeinschaft (DFG, Sociedade Alemã de Amparo à Pesquisa), agência estatal que financia a ciência na Alemanha, à semelhança do nosso Conselho Nacional de Desenvolvimento Científico e Tecnológico. Entre 1999 e 2005, foi assistente da cadeira de história da América Latina na mesma Universidade de Eichstätt. Em 2003, apresentou sua tese de livre-docência sobre história do futebol na América Latina em contexto global. Dois anos depois, tornou-se professor de história da América Latina no Instituto de Estudos Latino-americanos e no Instituto Friedrich Meinecke da Universidade Livre de Berlim, posto no qual permanece até hoje.

Rinke é historiador bastante prolífico. No ano passado foi publicado pela editora Theiss seu livro Kolumbus und der Tag von Guanahani, 1492: Ein Wendepunkt der Geschichte ${ }^{3}$ (Colombo e

\footnotetext{
${ }^{1}$ Freie Universität Berlin, 12 mar. 2013. Ver http://www.fu-berlin.de/pt/sites/brazil/pressemitteilungen/ Rinke_Einstein.html.

2 "Der letzte freie Kontinent": Deutsche Lateinamerikapolitik im Zeichen transnationaler Beziehungen, 1918-1933, Stuttgart, H.D. Heinz, 1996.
}

${ }^{3}$ Kolumbus und der Tag von Guanahani, 1492: Ein Wendepunkt der Geschichte, Stuttgart, Theiss, 2013. 
o "Dia de Guanahani", 1492: um momento decisivo da história), em que revisita a chegada de Colombo à América Latina, descentralizando a perspectiva narrativa habitual do episódio. Com Friedrich Schulze, também veio a lume em 2013 Kleine Geschichte Brasiliens ${ }^{4}$ (Breve história do Brasil), da série "Breves histórias", publicada pela editora C.H. Beck, no âmbito da qual Rinke publicou, em 2007, o volume concernente ao Chile. ${ }^{5}$ O país sul-americano foi tema de duas outras obras de Rinke, Begegnungen mit dem Yankee: Nordamerikanisierung und soziokultureller Wandel in Chile, 1898-19906 (Encontros com os yankees: americanização e transformação sociocultural no Chile, 1898-1990), publicada pela editora Böhlau em 2004, e Cultura de masas, reforma y nacionalismo en Chile, 1910-19317, publicada no Chile em 2002. Em 2012 foi lançado Lateinamerika und die USA: Eine Geschichte zwischen Räumen von der Kolonialzeit bis heute ${ }^{8}$ (A América Latina e os EUA: uma história entre espaços, da época colonial ao presente), que em certa medida retoma tema abordado pelo historiador em obra de 1992, Zwischen Weltpolitik und Monroe Doktrin: Botschafter Speck von Sternburg und die deutschamerikanischen Beziehungen, 1898-1908 (Entre a política e a doutrina Monroe: o embaixador Speck von Sternburg e as relações teuto-norte-americanas, 1898-1980).

Num esforço de promover o efetivo diálogo intelectual entre alemães e latino-americanos, algumas obras de Rinke têm sido traduzidas para o espanhol e o português. Em 2013 a editora da Direção de Bibliotecas, Arquivos e Museus (Dibam) de Santiago do Chile publicou Encuentros con el Yanqui: norteamericanización y cambio sociocultural en Chile, 1898-1990. Em 2012, a Editora da Pontifícia Universidade Católica do Rio Grande do Sul lançou História da América Latina: das culturas pré-colombianas até o presente ${ }^{10}$, tradução de Geschichte Lateinamerikas: Von den frühesten Kulturen bis zur Gegenwart ${ }^{11}$, editada na Alemanha em 2010. Em 2011 o Colégio do México publicou Las revoluciones en América Latina: las vías a la independencia, 1760-1830 ${ }^{12}$, tradução de Revolutionen in Lateinamerika: Wege in die Unabhängigkeit, 1760-1830 ${ }^{13}$, lançada em idioma alemão no ano anterior. Rinke também é autor de numerosos artigos publicados em revistas internacionais, tanto latino-americanas como alemãs e norte-americanas. Cultiva densa rede de contatos intelectuais com latino-americanos. Suas relações com o ambiente acadêmico brasileiro vêm-se estreitando bastante nos últimos anos.

\footnotetext{
${ }^{4}$ Kleine Geschichte Brasiliens, München, C.H. Beck, 2013.

${ }^{5}$ Kleine Geschichte Chiles, München, C.H. Beck, 2007.

${ }^{6}$ Begegnungen mit dem Yankee: Nordamerikanisierung und soziokultureller Wandel in Chile, 1898-1990, Köln, Böhlau, 2004.

${ }^{7}$ Cultura de masas, reforma y nacionalismo en Chile, 1910-1931, Valparaíso, Pontifícia Universidad Católica de Valparaíso; Centro de Investigaciones Diego Barros Arana, 2002.

${ }^{8}$ Lateinamerika und die USA: Eine Geschichte zwischen Räumen von der Kolonialzeit bis heute, Darmstadt, WBG, 2012.

${ }^{9}$ Zwischen Weltpolitik und Monroe Doktrin: Botschafter Speck von Sternburg und die deutsch-amerikanischen Beziehungen, 1898-1908, Stuttgart, H.D. Heinz, 1992.

${ }^{10}$ História da América Latina: das culturas pré-colombianas até o presente, Porto Alegre, EdiPUCRS, 2012.

${ }^{11}$ Geschichte Lateinamerikas: Von den frühesten Kulturen bis zur Gegenwart, München, C.H. Beck, 2010.

${ }^{12}$ Las revoluciones en América Latina: las vías a la independencia, 1760-1830, México, El Colegio de México/ Colegio Internacional de Graduados, 2011.

${ }^{13}$ Revolutionen in Lateinamerika: Wege in die Unabhängigkeit, 1760-1830, München, C.H. Beck, 2010.
} 
Em 2011, esteve na Casa de Oswaldo Cruz, onde proferiu palestra sobre o intercâmbio BrasilAlemanha até a Primeira Guerra Mundial e travou contato com pesquisadores e estudantes. Nessa ocasião aproveitamos a oportunidade para fazer a entrevista que se segue. Sua visita fez parte do esforço em consolidar parceria com o grupo de pesquisa coordenado por Magali Romero Sá e Jaime L. Benchimol, dedicado a refletir sobre trocas intelectuais do Brasil com Europa e EUA. Estudos sobre as relações com o mundo germânico vêm assumindo densidade crescente nos trabalhos desenvolvidos pelo grupo. A obra de Rinke constitui subsídio fundamental para os profissionais e alunos que analisam tais relações, procurando pensar o intercâmbio científico em suas correlações com as dinâmicas sociais, políticas e culturais. Num plano mais geral, suas reflexões extrapolam o âmbito do continente latino-americano e permitem pensar a globalização como processo histórico, situando contextos nacionais e regionais num quadro geral, marcado pela crescente compressão das distâncias e multiplicação das interações entre indivíduos, grupos, sociedades e formações políticas.

André Felipe Cândido da Silva

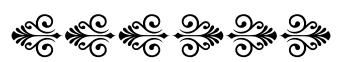

Gostaríamos que falasse um pouco sobre sua trajetória e formação, sobre como chegou à história da América Latina.

Quando obtive o Abitur, o certificado da escola secundária alemã, tinha a ideia de estudar história. Já aos cinco anos imaginava algum dia estudar história, porque sempre me fascinou. Quando menciono minha querida avó em minhas apresentações, não é só para divertir a plateia. Para mim sempre houve forte dimensão emocional, porque senhoras idosas, como minha avó, que eram viúvas, que haviam perdido seus maridos em diversas guerras, contaram-me sobre sua juventude, sobre suas vidas, vidas bastante tristes, e eu me perguntava por que havia tanta tristeza e tanta guerra em meu país. Desde cedo despertou em mim o interesse pela história, e creio que fui fortemente influenciado pelo fato de ter vivido com pessoas idosas, que me contaram muitas histórias. Sempre me fascinou essa dimensão da vida humana, do que se passou, do por que somos como somos agora, por que choramos no Dia dos Mortos... Isso, quando criança, você não entende, mas sente que é algo muito depressivo e triste, e acaba sendo marcado. Também havia em minha casa livros com ilustrações, e as imagens também têm forte influência na formação das pessoas, especialmente das crianças. As ilustrações também despertaram meu interesse pela história. O interesse pela América Latina foi algo que se desenvolveu mais tarde. Quando era adolescente, me dei conta de que a América Latina era um continente muito interessante, o continente das revoluções. Em minha adolescência estava em curso a revolução na Nicarágua (1979), e isso para nós era uma coisa muito boa, muito bem vista, era a luta contra os imperialistas yankees. Tínhamos então certa mobilização política, e aquilo chamou a atenção. Na minha infância testemunhei pela televisão cenas do golpe de Estado no Chile, em 1973, e me perguntei, como faria uma criança de apenas oito anos: por que o Exército bombardeava o próprio país, 
um palácio no centro da capital? Não entendia. Meu pai era trabalhador, é importante que saibam. Éramos da classe operária, e não houve em minha família ninguém com formação universitária antes de mim. Sou o primeiro. Vocês me perguntaram o motivo do meu interesse pela América Latina. Naquela época, ainda no contexto da guerra fria, falava-se muito sobre a região. Meu pai, como trabalhador, era de opinião que faziam bem em matar os comunistas. Tenho que mencionar que cresci em uma cidade pequena, muito próxima da fronteira entre as duas Alemanhas. Esse fator espacial era importante. Brincávamos na fronteira, e eu vi o que significava o comunismo em outro país, porque a fronteira era muito bem guardada, e parte de minha família vivia além dela, do outro lado da Alemanha, e não podia nos visitar, nem nós podíamos visitá-la. Era uma divisão muito forte. Esse sentimento sobre a guerra fria eu tive também, mas quando adulto, claro, adotei uma atitude mais crítica. Nesse momento a América Latina passou a me interessar muito; mas quando comecei a estudar história, não tinha a intenção de estudar história latino-americana. Na Alemanha a história da América Latina não se ensina em todas as universidades, é um ramo de estudo bastante marginal. Estuda-se em Berlim, Hamburgo, Colônia e Leipzig; esta, na época, ficava na República Democrática Alemã, portanto não era acessível para mim. Então comecei a estudar história em Bamberg, aquela história tout court, subdividida em antiga, medieval, Renascimento etc. Mas havia um professor chamado Hans-Joachim König, que era especialista em história latino-americana. Era um jovem sem posto fixo na Universidade de Bamberg, mas ministrava de vez em quando cursos de história latino-americana. Era um professor muito bom, um jovem muito motivado, ativo, muito diferente dos outros professores, já idosos e não muito motivados; então me senti atraído pela América Latina. Ao começar a estudar a história latino-americana, pude ver muitos processos que em meu país ganharam relevância há muitos séculos. Especialmente o fato da multietnicidade e multiculturalidade, que, em países como Brasil, Argentina e outros, faz conviverem, mais ou menos tranquilamente, distintas etnias, culturas, grupos imigrantes, em situação que, para mim, se parecia com a da Alemanha, que nas últimas décadas havia recebido forte imigração de diferentes partes do mundo, o que, como sabem, criou grandes problemas de xenofobia. Esse tipo de experiência latino-americana tem uma relevância que vai além de suas fronteiras, relevância para a compreensão do mundo moderno, por isso me fascinou...

\section{Estamos nos anos 1980.}

Sim, em 1984 obtive meu Abitur, depois tive que prestar o serviço obrigatório no Exército e em seguida comecei os estudos em Bamberg, os estudos normais em história, e nos últimos anos da década de 1980, em 1989, fiz minha dissertação de mestrado sobre as relações entre América do Norte e Alemanha. Isso porque decidi fazer estudos fora do país durante um ano e obtive uma bolsa para ir aos EUA. Fui e fiquei interessado nas relações entre aquele país e a Alemanha. Estudei-as sob a perspectiva de um embaixador atuante no período do Império alemão e escrevi a dissertação na Bowling Green State University, em Ohio. Depois, com poucas mudanças, aceitaram meu trabalho para a concessão do diploma na Alemanha. Era o momento, então, de um redirecionamento acadêmico. Durante as pesquisas sobre as relações entre Alemanha e EUA me dei conta de que a América Latina era um fator crucial. As rivalidades, toda a questão da doutrina Monroe, a crise política na Venezuela e também a 
forte presença do "perigo alemão" no Brasil influenciaram fortemente as relações entre EUA e Alemanha naquela época, pois, como vocês sabem, os EUA têm uma ideia bem imperialista do que seja a América Latina: parte de seu hemisfério; portanto os alemães deveriam ficar fora dele. Esse foi um aspeto interessante, que me fascinou. Então, depois de formado tive que optar por um novo direcionamento acadêmico e percebi por minhas leituras que ninguém sabia quase nada sobre as relações entre a América Latina e Alemanha no período da República de Weimar. A historiografia sempre se concentrou no Império alemão, isto é, no período anterior à Primeira Guerra Mundial, ou no período nazista. Não havia quase nenhum estudo sobre o período de Weimar, por isso decidi escrever uma tese de doutorado a esse respeito, e foi uma grande honra quando meu professor Hans-Joachim König convidou-me para ser seu orientando no doutorado. Além disso, tive a sorte de receber uma bolsa de estudo.

\section{Você já estava na Freie Universität?}

Não, isso ainda era em Bamberg. König mudou-se para a Universidade Católica de Eichstätt, e eu fui com ele, para fazer o doutorado. Tinha uma bolsa de três anos da Fundação Friedrich Ebert. Quando comecei tinha a esperança de que iria recebê-la por esse tempo, mas depois de dois anos disseram-me que tinham problemas financeiros e que não poderiam financiar o terceiro ano. Deram-me mais meio ano, apenas. Fui bolsista durante dois anos e meio que, claro, não foram suficientes para terminar a tese. Tive que trabalhar, arranjar outros empregos. Naquele momento me casei, e minha esposa tinha um emprego, o que nos ajudou enquanto eu trabalhava aqui e ali, dando aulas de alemão e de história. Assim terminei minha tese, em 1994, sem muito dinheiro, e a defendi no começo de 1995. Este é outro ponto-chave na vida de um acadêmico: o que fazer depois do doutorado? Para mim não era uma decisão fácil, pois estava casado, queria ter filhos, e, no mundo acadêmico alemão, uma carreira acadêmica é muito árdua, problemática, pois nunca se sabe se se terá êxito ou não. Por isso não estava muito decidido. Mesmo assim, enviei um projeto de pesquisa à Deutsche Forschungs Gemeinschaft (DFG, Sociedade Alemã de Amparo à Pesquisa), uma das maiores instituições na Alemanha para a formação de jovens em estágios pós-doutorais. Ao mesmo tempo mandei solicitações a outras instituições, a algumas bibliotecas de pesquisa... Aceitaram-me para um programa de estudo como bibliotecário-pesquisador. Mal havia começado, recebi uma resposta positiva da DFG, que aceitava meu projeto também. Tive sorte porque a DFG me deixou começar o trabalho como bibliotecário, mas depois de três meses teria de decidir por uma ou outra coisa. Depois de três meses trabalhando nas regras de catalogação da biblioteca, percebi que aquilo não era para mim e voltei à carreira acadêmica.

O senhor já trabalhou com história das ciências? Se não, o que espera de uma eventual parceria com alguém que tem como tema principal a história das ciências ou da saúde?

Isso é um desenvolvimento recente. Como vocês sabem, me interessaram as relações econômicas, políticas e culturais entre Alemanha e América Latina. Esse foi meu ponto de partida e o tema de minha tese de doutorado. Agora, com vários doutorandos pesquisando temas similares de transferências culturais, de circulação de ideias, essas temáticas passaram também a me interessar. Por exemplo, na Argentina tenho há muitos anos um amigo, Mariano Plotkin, que estuda a difusão da psicanálise e me convidou para fazer parte de seu 
grupo de trabalho sobre os intercâmbios entre Argentina e Alemanha. Sendo membro desse grupo também participei de encontros como o que houve em Paris ${ }^{14}$, em que se discutiram exatamente esses assuntos de intercâmbios entre cientistas e médicos. Isso me interessa, mas não do ponto de vista do desenvolvimento das ideias científicas, porque não sou especialista em biologia ou química, mas sim pelos aspectos institucionais, os aspectos culturais da transferência e da circulação do conhecimento, que tipos de rede existiam e que problemas eram colocados no âmbito dessas redes, em que momento elas se criam e se dissolvem... são estas as perguntas que realmente me interessam. Quer dizer, provavelmente não me transformarei em historiador das ciências ou da saúde, mas em historiador desse tipo de história compartilhada, dos intercâmbios de ideias e instituições. Por isso me interessa o que é feito aqui na Fiocruz, especialmente na área dos intercâmbios científicos, que eu desconhecia. Examinar as articulações que algumas pessoas alcançaram com suas redes pessoais é muito importante para entendermos o funcionamento atual dessas redes nesses tipos de instituição.

Vivemos num mundo globalizado e nosso olhar está agora muito voltado para como começaram essas interações. Temos produzido muitos trabalhos sobre como os cientistas interagiam em épocas passadas, através de cartas, trabalhos científicos e outros meios, conscientes de que isso tem muita relação com o que fazemos hoje, com nossas escolhas.

Por isso, acredito, cresceu tanto o interesse por esses temas. Impressiona-me a quantidade de redes que existem agora e o número de convites que recebi para juntar-me a elas. Recebi convites de Alexis de Greiff, da Colômbia, da Denis Diderot [Université Paris Diderot - Paris 7], da Inglaterra, do Chile... Há muitos grupos que estão pesquisando a questão central da circulação do conhecimento, à luz de diferentes perguntas e temáticas. É o grande tema da atualidade, que diz respeito a como conviver com a transformação secular que estamos presenciando, como lidar com os saberes que estão no mercado, pelo simples fato de que existe a internet e podemos nos informar sobre tantas coisas. Certamente esse tema tem altíssima relevância para nossa realidade e explica o interesse das fundações em gastar dinheiro com esse tipo de pesquisa.

Gostaríamos que falasse um pouco sobre o Instituto em que trabalha, na Universidade Livre de Berlim.

O Instituto de Estudos Latino-americanos foi fundado em 1970, e recentemente fizemos uma comemoração especial pelos seus quarenta anos de existência. O Instituto formou-se no contexto do movimento de rebelião estudantil na Alemanha, mais ou menos em 1968. Rudi Dutschke, a grande figura do movimento estudantil em Berlim, era um entusiasta das teorias de Che Guevara. Esse mito revolucionário latino-americano era muito importante como fonte de inspiração para os estudantes alemães. Desse espírito nasceu a ideia de se fundar um instituto que se dedicasse somente à realidade latino-americana. Já existia na Universidade um instituto de estudos norte-americanos, John F. Kennedy Institute, que tem a ver com a história da Freie Universität. Sua fundação foi fortemente influenciada pela ocupação norteamericana de Berlim. Como vocês sabem, depois da Segunda Guerra Mundial, Berlim era

${ }^{14}$ O colóquio "Mobilités et circulation des savoirs" teve lugar na Université Paris Diderot - Paris 7, em novembro de 2011. 
uma cidade dividida, e a parte ocidental era controlada pelos norte-americanos, franceses e ingleses, ao passo que o setor oriental foi dominado pelos soviéticos. A Humboldt Universität estava localizada no setor oriental, e naquela época tinha ainda o nome de Kaiser-FriedrichWilhelm-Universität. Nos anos 1940 os comunistas fizeram muita pressão para transformá-la numa universidade comunista e para expulsar de lá todos os "burgueses". Houve fuga de professores e estudantes liberais e democratas para a parte ocidental, onde, com a ajuda dos EUA, fundaram uma nova universidade, por isso chamada de Freie Universität [Universidade Livre]. Isso influenciou muito o seu programa: uma universidade livre das influências das ideologias, livre para desenvolver-se no mundo acadêmico, sem nenhuma influência. Devo, porém, dizer que a influência dos estudos norte-americanos era importante, porque não vivíamos num vácuo. Os EUA disponibilizaram muitos recursos para criar a universidade, mas em 1968, como disse, um pouco da rebelião também se dirigiu contra as influências norte-americanas, o que resultou na formação do Instituto de Estudos Latino-americanos. Nosso Instituto teve, desde o começo, seis disciplinas fundamentais, seis cátedras: antropologia cultural, literatura, economia, sociologia, ciência política e história. Seis catedráticos ministram essas disciplinas fundamentais. Somos o maior instituto do gênero em países de língua alemã, o que para nós é muito importante. O Instituto é pequeno, mas temos um grupo de jovens pesquisadores, dez posições, nas diferentes disciplinas.

A história no Instituto tem uma trajetória interessante, pois sempre houve muitas discussões políticas internas. O Instituto era considerado de esquerda, de espírito revolucionário, e a primeira geração de professores inspirou-se muito na teoria da dependência e na teoria da libertação. Era o pensamento fundamental para a formação do Instituto e para muitas das brigas políticas estudantis no âmbito da Freie Universität, que em certo sentido tinham a ver com a prática de nosso Instituto. Mais tarde, depois da revolta estudantil, houve várias discussões com a direção da Universidade, e o meu Instituto tem sido parte da resistência dentro dela. Depois da queda do muro de Berlim, isso começou a mudar. Claro que a ideologia de esquerda não se perdeu, tanto em Berlim quanto na América Latina. Mais tarde houve uma reorientação.

Após a reunificação de Berlim, a cidade passou a ter muitos problemas financeiros. Se ela fosse um estado federal da Alemanha, seria o estado mais pobre do país, com taxa de desemprego muito alta. Depois de quase quarenta anos de separação, Berlim perdeu quase todas as grandes empresas que foram para a Baviera, Baden-Württemberg e outras partes da Alemanha. A cidade acabou quase sem setor industrial, e isso é um problema, claro. Tem muitos museus, teatros e óperas, mas isso custa dinheiro, e alguém tem que ganhar esse dinheiro, mas não havia quem o fizesse... um problema. Nessa época fazia parte do cenário político de Berlim a ideia de uma reforma, para de alguma maneira se poupar dinheiro. Temos agora duas universidades, a Humboldt e a Freie Universität, além de uma universidade técnica, então são três grandes universidades. Devia-se cuidar delas, e se fosse realmente necessário ter, por exemplo, uma cátedra de história da África, seria melhor ter somente em uma das universidades. Então muitas cátedras foram fechadas. Minha universidade, por exemplo, perdeu mais da metade dos professores em uma década, enquanto o número de estudantes cresce até hoje. Naquela época também se discutiu a permanência ou não do Instituto de Estudos Latino-americanos, mas tivemos sorte, primeiro porque, de certa forma, o Instituto é 
único na Alemanha. As pessoas afinal perceberam que seria uma grande perda extinguir um instituto daquele porte. Além disso, sabiam que havia uma mudança geracional dentro do Instituto, pois, com a aposentadoria de professores, dentro de quatro ou cinco anos seriam abertas vagas. Houve também a chegada de professores mais jovens, com mais ou menos a minha idade. Tivemos assim a oportunidade de promover um novo começo para o Instituto. $\mathrm{Eu}$ diria que esse recomeço aconteceu em 2004. Primeiro tivemos que preencher o vazio deixado pelos professores, processo que se prolongou até 2008. Agora temos novamente seis professores, com suas respectivas cátedras. Temos tido sucesso ultimamente, têm aparecido grandes projetos, com fundos de financiamento. Os dois maiores são projetos relacionados a espaços. ${ }^{15} \mathrm{O}$ projeto em colaboração com o Colégio Internacional de Graduados (CIG $)^{16}$ é de muito prestígio, porque é o primeiro grande programa de doutorado internacional entre Alemanha e América Latina em humanidades e ciências sociais, e o primeiro com o México em todas as ciências. Nisso está o caráter pioneiro, o que significa muito trabalho, porque temos duas culturas administrativas muito distintas e também porque o número de participantes é grande: um grupo de dez professores catedráticos alemães e cerca de dez mexicanos. É um programa muito bom, gostamos da colaboração e aprendemos mutuamente. Outro projeto é o dos colegas de ciências sociais, o desiguALdades.net. ${ }^{17}$ Tem o objetivo de criar uma rede envolvendo ciências sociais, sociologia, ciência política e antropologia para estudar a desigualdade na América Latina, também em uma dimensão inovadora, posto que sob uma perspectiva transnacional. Esse projeto oferece muitas bolsas para as quais podemos convidar pessoas especialmente da América Latina, porque, além do programa com doutorandos, temos uma bolsa para estada mais curta, de poucos meses, para estabelecer contatos, fazer pesquisa, esse tipo de coisa.

Além dos grandes projetos, os catedráticos também têm bolsas para os vários projetos de pesquisa sob sua responsabilidade. Nesse sentido, temos tido muito sucesso, muito mais do que a geração anterior. Recebemos financiamentos externos, ganhamos competência e conquistamos visibilidade no mundo acadêmico; não somente na Alemanha, mas na América Latina (para nós o mais importante), EUA, Inglaterra e França. Agora sou vicepresidente da Associação de Historiadores Latinoamericanistas Europeus [Ahila], a maior associação internacional de historiadores de América Latina, e em 2014 vamos promover o congresso da Ahila, em Berlim, para o qual vocês já estão convidados. Irão participar muitos pesquisadores do Brasil, do México e de toda a América Latina. A metade dos membros é de latino-americanos, a outra metade, de europeus, de países como França, Rússia, Polônia, Inglaterra, Espanha, Alemanha etc. Isso é o bonito, porque assim se pode criar uma rede de contatos na Europa que realmente valha a pena.

\footnotetext{
${ }^{15}$ De um desses projetos resultou o livro Entre espacios: movimientos, actores y representaciones de la globalización, de Carlos Alba, Marianne Braig, Stefan Rinke e Guillermo Zermeño (Ed.), Berlim, Walter Frey Verlag, 2013.

${ }^{16}$ O CIG, patrocinado pela Deutsche Forschungsgemeinschaft (Fundação Alemã de Investigação), promove o intercâmbio entre pós-graduandos em ciências sociais e humanidades das três universidades da área de Berlim, a Universidade Livre de Berlim, a Universidade de Potsdam e a Universidade Humboldt, e três instituições mexicanas, o Centro de Pesquisas e Estudos Superiores em Antropologia Social, o Colégio do México e a Universidade Nacional Autônoma do México.
}

${ }^{17}$ Ver www.desigualdades.net. 


\section{Na Frei Universität há outro instituto na área de história, não?}

Sim, o Instituto Friedrich Meinecke. Antes tenho que contar o restante da minha trajetória como historiador. Mais ou menos quando terminei meu doutorado, consegui a bolsa de pósdoutorado da DFG e decidi trabalhar sobre a norte-americanização de nossa cultura popular. No Chile me dei conta de que havia certos paralelismos entre o caso alemão e o chileno no entreguerras, e resolvi escrever sobre o caso chileno ao longo do século XX. Terminei esse estudo e fiquei "habilitado". Aqui no Brasil não há correspondência. É como um segundo doutorado, necessário para qualificar um professor. Havia conseguido a Habilitation em 2004, na Universidade Católica de Eichstätt, e com isso tinha qualificação para trabalhar como docente, mas não tinha emprego. Depois da defesa dessa tese, a pessoa deve mudar de universidade. Para evitar o "incesto", nunca, ou quase nunca, um professor vai ganhar um posto na mesma universidade na qual defendeu sua Habilitation. Se compararmos com os sistemas universitários de outros países, penso que é bom, porque evita as fortes correntes que se formam nas instituições. Mas é um pouco complicado, claro, o sistema não é perfeito, para nós significa muita insegurança nessa fase da vida. Eu já tinha dois filhos e não sabia o que ia acontecer comigo e com minha família, mas em 2005 fui chamado para Berlim, para a cátedra de história latino-americana, uma das poucas que há na Alemanha. Foi uma sorte conseguir essa vaga, e comecei a estruturar o programa...

\section{No Instituto Meinecke...}

Sim, integrando-me à Freie Universität e ao Instituto de Estudos Latino-americanos, passei a ser também membro do Instituto de História, o Instituto Friedrich Meinecke. Meinecke é considerado um dos maiores historiadores alemães, o grande historiador da República de Weimar e também do Império. Quando fundaram a Freie Universität em 1948 ele tinha 86 anos e morreu logo em seguida, mas foi um dos fundadores da universidade, tendo sido seu primeiro reitor. O Friedrich Meinecke é um bom instituto, no qual temos colegas muito bons e com o qual temos muitos projetos em comum. ${ }^{18}$ Para mim essa conexão é importante porque no Instituto de Estudos Latino-americanos não é possível fazer um doutorado. Quer dizer, mesmo que alguém seja latino-americanista, estuda e faz sua tese de doutorado comigo, mas para todo o trâmite, para o exame e todo o resto, tem que ir ao Departamento de História. Somos historiadores no final das contas. Isso é importante também porque não há cátedras de estudos latino-americanos, há cátedras de história da América Latina. E agora somos dez; crescemos; recentemente ganhamos dois novos postos na Alemanha para nossa disciplina. Isso significa muito, porque antes corríamos o risco de perder cátedras, e recentemente criaram uma em Hannover e outra em Bremen. Isso demonstra que o interesse pela história da América Latina aumentou no âmbito da história, o que tem a ver com a nova onda da história global. O efeito é muito positivo porque agora os historiadores tout court precisam de nós, pois não sabem muito sobre a América Latina, e quando precisam escrever algo sobre a história global

${ }^{18}$ No ranking de 2014 da QS (Quacquarelli Symonds University Rankings, organização internacional de pesquisa em educação que avalia o desempenho de instituições de ensino médio, superior e de pós-graduação), o Instituto Friedrich Meinecke ficou em 14을 lugar no mundo e em primeiro lugar na Alemanha entre as instituições acadêmicas dedicadas à pesquisa e ao ensino de história. Ver http://www.topuniversities.com/ subject-rankings. 
têm que discutir conosco, estão abertos a isso. A nova geração de historiadores tem outra forma de pensar. Antes eram, na maioria, eurocentristas, mais do que isso, germanocentristas. Para eles, o que tinha interesse era a história da Alemanha e nada mais. Isso mudou, a história se abriu, e por isso ocupamos agora um lugar um pouco mais central do que o que ocupávamos antes. Os colegas nos perguntam se não queremos participar neste congresso ou naquela série de artigos, e isto é um desenvolvimento muito bom, muito positivo para a disciplina que representamos: a história latino-americana.

Pode aprofundar um pouco mais a questão da recepção dos estudos sobre a América Latina na Europa atualmente?

Talvez possa acrescentar que realmente houve um período em que os estudos latinoamericanos estavam em crise, e não era somente por falta de motivação dos colegas, mas porque depois da Queda do Muro todo o interesse se voltou para o leste da Europa. Houve então uma espécie de bonança para os colegas que a estudavam. Receberam muitos financiamentos para pesquisa, foram criadas novas cátedras, foi uma época incrível, mas, para nós, problemática, porque a América Latina ficou à margem, em dimensão realmente muito pequena no interesse público. Isso mudou no início do novo século, o que em parte se pode relacionar à volta ao poder de governos de esquerda na América Latina, como o de Lula, também ao modelo bem-sucedido do Brasil, e creio que agora, na Alemanha, o interesse pelo Brasil é grande. Isso de deve essencialmente a razões econômicas, à existência de um mercado aberto, novo, para seus produtos, interesses e investimentos, e isso explica por que há fundos para o intercâmbio acadêmico.

Você disse que hoje a América Latina tem grande importância, também no mundo acadêmico. Poderia falar sobre os distintos momentos de interesse dos alemães pela América Latina, desde os anos 1920, e da imagem que os alemães tinham desta parte do mundo?

É sempre muito complicado encontrar imagens, eu diria que algumas percepções dominam mais que outras em determinadas épocas. Nos anos 1920 existia uma forte ideia de superioridade da cultura alemã, e, claro, nos anos 1930, com os nazistas. Ao mesmo tempo, houve certa valorização do que significava a América Latina como conjunto de países abertos e interessados em cultura e ciência alemãs. Em comparação com outras regiões do mundo, como a Ásia, observou-se que América Latina tinha maior interesse e valorizava mais a ciência e a cultura alemãs. Isso é evidente; na literatura, na música e no teatro da época pode-se constatar que a América Latina e em particular o Brasil eram vistos como regiões muito exóticas. Tal exotismo perdurou no período posterior à Segunda Guerra Mundial, mas com um sentido diferente, relacionado à ascensão da esquerda. O que os esquerdistas fizeram nada mais era do que outra forma de exotismo: projetaram no continente latino-americano os desejos de o ver como continente da revolução pura e boa. Até os anos 1980 uma forte corrente no pensamento alemão mais progressista via a América Latina como um continente de sonho. Sonho revolucionário, da promessa de revolução, e muitos não se deram conta de que se praticavam crimes contra a liberdade de pensamento em Cuba e em outros lugares. Acredito que não havia uma atitude crítica; essa perspectiva não tinha a ver com a realidade latino-americana. Era também uma maneira de projetar seus próprios desejos 
e um pensamento de superioridade sobre esse continente. Acredito que desde a Queda do Muro as coisas mudaram lentamente, e vemos com mais objetividade o que se passou e o que está se passando. Podemos falar com nossos colegas latino-americanos e não sobre os colegas latino-americanos, e isso foi uma mudança fundamental. Aprendemos que nosso sistema tão bonito, seja de esquerda ou capitalista, não funciona muito bem porque temos muitos problemas e podemos aprender com as experiências latino-americanas. Mas ainda existe a ideia do exotismo. Às vezes, quando tenho jovens estudantes no primeiro semestre, muitos deles vêm com essa ideia de Che Guevara, com camisetas que ostentam sua imagem; esses mitos seguem existindo, mas eu acredito que a ideia geral mudou muito; agora temos mais distanciamento e mais intercâmbio intelectual. Cresceram muito as possibilidades de interatuar, de convidar pessoas, ficar um período na América Latina ou trazer latino-americanos para a Alemanha. Existem muito mais possibilidades, e as pessoas as utilizam; temos que discutir de maneira diferente e aprender algo mutuamente com essa convivência. Isso é importante para um instituto como o nosso, o Instituto de Estudos Latino-americanos, que existe exatamente para fomentar este intercâmbio que a todos interessa. Felizmente temos bom número de convidados de todos os países latino-americanos que vêm a Berlim, nos visitam e fazem seus estudos conosco.

Você falou antes de lógicas administrativas diferentes ao se referir ao projeto com o México. Sabemos que há vontade de cooperar, de ambas as partes, o que é bom para todos, mas também há dificuldades. Como vê isso?

Engraçado, os problemas que temos são similares, são os problemas que os acadêmicos sempre têm com a administração de suas universidades. Se vamos fazer algo novo sempre há dúvidas da parte das administrações, porque dá trabalho, mais problemas... Um programa mexicano e alemão tem que lidar com duas administrações que vão ter alguma resistência a inovações, não querem mudar o modo como sempre fizeram as coisas. Isso é um problema que temos nós e os colegas mexicanos. Claro que diferem as maneiras como são formados os doutorandos. No sistema alemão há muita independência para a escolha do tema, e o aluno o discute abertamente com seu orientador. Mas ao longo da pesquisa, os contatos não são tão intensivos quanto aqui. Na Alemanha praticamente não há exigência de cursar disciplinas durante o doutoramento. É somente a tese e a sua defesa, nada mais.

\section{Quantos anos para o doutorado, quatro?}

Não, normalmente as pessoas precisam de mais. Em história os mais rápidos normalmente precisam de quatro anos, mas muitos necessitam cinco, seis ou sete anos. Estamos tentando mudar isso. Com o CIG, os estudantes que estão integrados recebem uma nova forma de tutoria por parte dos professores, o que é uma novidade, pois temos muito mais contato com eles do que com os doutorandos, digamos, "normais". A primeira geração deverá concluir seus trabalhos no ano que vem, e esperamos que consigam realmente terminar, porque não podemos dar-lhes mais do que três anos de financiamento. Mas na formação doutoral alemã há certa tendência à "inflação" de páginas. Minha tese de doutorado tinha oitocentas páginas. Agora, vendo de certa distância, sei que deveria ter feito diferente. Na época tive influências externas e havia essa tendência de "inflação" do número de páginas das teses doutorais, 
agora, como professores, pressionamos para que o doutorando termine mais cedo e apresente trabalhos mais curtos: com meus alunos tenho estabelecido um limite de trezentas páginas, não posso aceitar mais. Tem a ver também com o fato de eu ter trinta doutorandos e não poder ler mil páginas de cada um. Iria morrer lendo teses. É uma nova tendência, realmente mudou a maneira de escrever academicamente, e creio que é bom, mas precisamos ter cuidado para não perder o bom do estudo, os detalhes, que também são importantes.

\section{E se uma tese tiver oitocentas páginas?}

Também aceito, mas veja: minha primeira doutoranda, que terminou há pouco, é da primeira geração de doutorandos, pois começamos há cinco anos. Ela escreveu duzentas e cinquenta páginas e ganhou dois prêmios com isso. Ela recebeu o maior prêmio de universidade, e agora, o prêmio do departamento de história. Isso significa muito, pois o mundo é muito competitivo e, ao final, chegamos à conclusão de que fizemos algo bom. Sempre acreditei em certa flexibilidade, dependendo da pessoa, de sua maneira de trabalhar, do tema. Bem... se todos os trinta doutorandos me entregarem mais que trezentas páginas, seria um problema.

No momento, a historiografia utilizada na Alemanha muito se refere à história global, história transnacional, e seu trabalho foi um dos primeiros a seguir essa tendência, que parece ser muito forte agora na historiografia europeia. Gostaria que comentasse brevemente, depois de ter falado sobre o novo paradigma na escrita da história, como eles se relacionam na historiografia em geral? As inovações e continuidades...

Acho que eu seria um pouco mais modesto e não diria paradigma, porque talvez seja um pouco exagerado. A história transnacional integra e está mais ou menos presente em muitas das histórias existentes. Tem a ver com história social, história econômica, história das ideias, história da cultura e, claro, a história das relações internacionais. A história transnacional é como um novo ponto de vista e não uma grande teoria. Nos textos que tratam da história transnacional ou global não se encontra a grande teoria da história porque é exatamente o contrário. Não quer ser uma nova maneira de explicar toda a história, mas uma perspectiva de abordar problemas que já eram explicados de alguma forma, de modo a mostrar que há mais dimensões que possibilitam compreendê-los. Esse é o lado bom e inovador dessa abordagem. Significa que na historiografia agora podem conviver tranquilamente diversas abordagens, não há necessidade de brigas a respeito dos fundamentos, como acontecia nos anos 1960, entre a história social e a tradicional história política. Eles discutiram muito porque cada uma das abordagens pretendia negar o direito de existência da outra, e isso fazia parte da guerra fria e do espírito ideológico da época, que agora podemos "historicizar". Tivemos essa briga na Alemanha, da escola de Bielefeld contra os tradicionalistas da história política. Eu diria que hoje não há esse tipo de briga, não há resistência à história transnacional, mesmo que muita gente se declare cética e que outros, que não gostam de aprender línguas, não gostam de viajar, fiquem na Alemanha com as suas atividades e continuem fazendo as coisas que sempre fizeram. Tudo bem, não há problema nisso, mas eu acredito que a historiografia de maior sucesso, mais inovadora no momento vem de parte da história transnacional e também da história global. Para mim, pelo menos, aproximar-me das perguntas que me interessam 
por esse prisma abre novas janelas sobre o passado, o que é sempre bom. Não é por outra razão que investigamos a história, senão para abrir novas janelas, olhar de maneira diferente coisas do passado que já sabíamos que existiam, mas que agora, sob essa perspectiva, são vistas de maneira diferente.

Aqui no Brasil é muito forte a retomada da historiografia alemã via Koselleck. Como podemos conhecer um pouco mais da historiografia alemã além dele? Que lugar poderia ocupar na historiografia transnacional? Há algo mais que possamos discutir em termos historiográficos com os alemães?

Considero que a história dos conceitos de Koselleck, no final dos anos 1970 e início dos 1980, era muito importante, e até hoje é muito interessante. Sabe que os espanhóis têm um projeto chamado "Iberconceptos" [conceitos ibéricos]? ${ }^{19}$ Publicaram um volume no ano passado, monumental, que estuda exatamente essas mudanças dos conceitos de nação e cidadania no período das colônias tardias e da Primeira República. ${ }^{20}$ Koselleck escreve sobre o caso europeu também em seu livro Begriffsgeschichten ${ }^{21}$ [Histórias dos conceitos]. Isso me interessa muito, mas é algo que já se pode fazer em Israel, na Ásia e na África... é importante fazê-lo, mas não é inovador. Inovadora é a história transnacional. Está em tradução um livro importante do historiador mais conhecido na Alemanha atualmente, Jürgen Osterhammel, que ganhou o prêmio Leibniz em 2010. ${ }^{22}$ Provavelmente é o melhor pesquisador de sua geração. Publicou um livro de 1.570 páginas - falamos há pouco da inflação de páginas! -, que se chama Die Verwandlung der Welt ${ }^{23}$ [A transformação do mundo]. Trata-se de uma história global do século XIX. Esse livro teve enorme êxito na Alemanha. Nunca se pensou que um livro desse tamanho venderia tanto, mas foi também um êxito comercial, vendeu não sei quantas cópias, e a editora ficou absolutamente surpresa com isso. No início teve medo de publicar, devido ao tamanho. O livro vendeu loucamente e está sendo traduzido para inglês e espanhol. Não é um livro sobre teoria, é mais do que isso: é uma maneira de colocar a teoria e a perspectiva transnacional e global em prática. Acredito que isso vá estimular uma discussão na América Latina também; espero que sim, pois acredito que com isso se possa trabalhar e abrir novas janelas para pesquisas. E vocês, nos temas que trabalham, estão já bem direcionados. Como catedrático sou membro de muitas comissões e estamos buscando novos professores, e em história, agora, os candidatos que escolhemos têm a ver com história transnacional, caso contrário não os recrutamos. Acreditamos que isso seja importante, o mais inovador que há, e nós, como a melhor universidade alemã em humanidades e ciências sociais, queremos os mais inovadores. Não queremos pessoas boas que fazem apenas o que faziam as gerações anteriores, mas que abram um novo campo de conhecimento. Assim, acredito que,

\footnotetext{
${ }^{19}$ Ver http://www.iberconceptos.net/pt-pt/.

${ }^{20}$ Diccionario político y social del mundo ibero-americano: la era de las revoluciones, 1750-1850, v.1, Javier Fernández Sebastián (Dir.), Madrid, Centro de Estudios Políticos y Constitucionales, 2009.

${ }^{21}$ Begriffsgeschichten: Studien zur Semantik und Pragmatik der politischen und sozialen Sprache, Frankfurt a.M., Suhrkamp, 2006.

${ }^{22} \mathrm{O}$ prêmio Leibniz é a mais importante premiação de incentivo à pesquisa da Alemanha. Ver http://www. dfg.de/en/funded_projects/prizewinners/leibniz_prize/index.html.

${ }^{23}$ Die Verwandlung der Welt: eine Geschichte des 19. Jahrhunderts, München, C.H. Beck, 2009.
} 
com os temas que vocês trabalham, aqui na América Latina, também vai acontecer esse tipo de abertura. A historiografia acolhe ao longo do tempo determinadas tendências, e penso que este é o momento da história global, transnacional. Em Berlim, em 2014, teremos o 17o Congresso Internacional da Ahila, "Entre espaços: a história latino-americana no contexto global", aberto exatamente para esse tipo de pergunta.

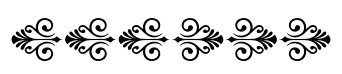

